\title{
Electronic Pill Bottles or Bidirectional Text Messaging to Improve Hypertension Medication Adherence (Way 2 Text): a Randomized Clinical Trial
}

\author{
Shivan J. Mehta, MD, MBA, MSHP ${ }^{1,2,3}$, Kevin G. Volpp, MD, PhD 1,2,3,4, \\ Andrea B. Troxel, SCD ${ }^{5}$, Susan C. Day, $M D^{7}$, Raymond Lim, $M A^{2,3}$, Noora Marcus, $M A^{2}$, \\ Laurie Norton, $\mathrm{MA}^{2}$, Sophia Anderson, $B A^{2}$, and David A. Asch, MD, MBA ${ }^{1,2,3,4}$
}

\begin{abstract}
'Department of Medicine, Perelman School of Medicine, University of Pennsylvania, Philadelphia, PA, USA; ${ }^{2}$ Center for Health Incentives and Behavioral Economics, Leonard Davis Institute of Health Economics, University of Pennsylvania, Philadelphia, PA, USA; ${ }^{3}$ Penn Medicine Center for Health Care Innovation, University of Pennsylvania, Philadelphia, PA, USA; ${ }^{4}$ Center for Health Equity Research and Promotion, Philadelphia VA Medical Center, Philadelphia, VA, USA; ${ }^{5}$ Division of Biostatistics, Department of Population Health, NYU School of Medicine, New York, NY, USA.
\end{abstract}

BACKGROUND: Poor medication adherence contributes to inadequate control of hypertension. However, the value of adherence monitoring is unknown.

OBJECTIVE: To evaluate the impact of monitoring adherence with electronic pill bottles or bidirectional text messaging on improving hypertension control.

DESIGN: Three-arm pragmatic randomized controlled trial. PATIENTS: One hundred forty-nine primary care patients aged 18-75 with hypertension and text messaging capabilities who were seen at least twice in the prior 12 months with at least two out-of-range blood pressure (BP) measurements, including the most recent visit.

INTERVENTIONS: Patients were randomized in a 1:2:2 ratio to receive (1) usual care, (2) electronic pill bottles for medication adherence monitoring (pill bottle), and (3) bidirectional text messaging for medication adherence monitoring (bidirectional text).

MAIN MEASURES: Change in systolic BP during the final 4-month visit compared with baseline.

KEY RESULTS: At the 4-month follow-up visit, mean (SD) change values in systolic blood pressure were - 4.7 (23.4) $\mathrm{mmHg}$ in usual care, $-4.3(21.5) \mathrm{mmHg}$ in the pill bottle arm, and -4.6 (19.8) $\mathrm{mmHg}$ in the text arm. There was no significant change in systolic blood pressure between control and the pill bottle arm $(p=0.94)$ or the text messaging $\operatorname{arm}(p=1.00)$, and the two intervention arms did not differ from each other $(p=0.93)$.

CONCLUSIONS: Despite good measured adherence, neither feedback with electronic pill bottles nor bidirectional text messaging about medication adherence improved blood pressure control. Adherence to prescribed medications was not improved enough to affect BP control or it was not the primary driver of poor control.

Previous Presentation An earlier version of this manuscript was presented at AcademyHealth in June 2018.

Electronic supplementary material The online version of this article (https://doi.org/10.1007/s11606-019-05241-x) contains supplementary material, which is available to authorized users.

Received November 7, 2018

Revised April 30, 2019

Accepted July 17, 2019

Published online August 8, 2019
TRIAL REGISTRATION: clinicaltrials.gov (NCT02778542)

KEY WORDS: hypertension; medication adherence; health behavior; primary care.

J Gen Intern Med 34(11):2397-404 DOI: $10.1007 / \mathrm{s} 11606-019-05241-\mathrm{x}$

(c) Society of General Internal Medicine 2019

\section{INTRODUCTION}

Hypertension affects about $30 \%$ of US adults and is a leading contributor to the global burden of disease. ${ }^{1-3}$ Despite substantial evidence that low-cost and readily available medications can improve clinical outcomes, ${ }^{4}$ only about half of patients have adequately controlled blood pressure (BP). ${ }^{5}$ Many studies show that adherence to hypertension medications is low ${ }^{6}$ and that poor adherence is associated with poor outcomes. ${ }^{7-10}$ Like many other chronic conditions, successful management of hypertension requires patient engagement on a daily basis, outside of clinical visits. ${ }^{11}$

Recent years have seen the introduction of technologies to measure and monitor medication adherence, such as electronic pill bottles. ${ }^{12-15}$ These pill bottles can connect wirelessly to software platforms to automate engagement with patients. There is some evidence that patients who use these devices and receive feedback have improved medication adherence in chronic conditions such as HIV and cardiovascular disease. ${ }^{16-}$ ${ }^{21}$ However, these devices are costly to implement and challenging for some patients, as they may require patients to decant medications from their original packaging into the devices and may require complicated processes to establish and maintain connectivity to wireless networks.

Text messaging holds promise for engagement of patients about medication adherence. Text messaging is now a leading communication channel and because of its ease and low technical threshold, its use spans demographic and economic barriers. ${ }^{22}$ Bidirectional text messaging offers the opportunity to monitor adherence by daily questioning of patients about whether they took their medications. ${ }^{23}$ These structured data 
responses might replace electronic pill bottle opening data, but they might also be less reliable than observed pill bottle openings. Patients can of course open pill bottles and not take the medication, but that kind of intentional non-adherence is a different clinical problem. Patients' text responses might more easily misrepresent actual pill taking.

Some studies have shown that both bidirectional and unidirectional text messaging can improve medication adherence in hypertension, but these studies have relied mainly on selfreport of adherence and do not consistently show improvement in clinical outcomes. ${ }^{24-28}$ There are a few studies showing that remote monitoring of BP in hypertension can improve clinical outcomes, but these rely on nurses or pharmacists to monitor the data, which can be costly for routine primary care practices to sustain. ${ }^{29-31}$ Additionally, for many clinicians, remote monitoring of BP creates an unwelcome sense of responsibility to respond to readings out of range.

Monitoring of medication adherence has the potential to improve hypertension management without creating the same unwelcome sense of responsibility, but rigorous evidence is needed about its effectiveness. In this study, we compare the effectiveness of electronic pill bottles and bidirectional text messaging at improving medication adherence and BP control among patients with poorly controlled hypertension.

\section{METHODS}

\section{Study Design}

This was a three-arm pragmatic randomized controlled trial comparing the following approaches to reduce blood pressure among patients with uncontrolled hypertension: (1) usual care; (2) electronic pill bottle to encourage medication adherence; and (3) bidirectional text messaging to encourage medication adherence. The University of Pennsylvania Institutional Review Board approved the study. Patients provided informed consent prior to enrollment. The protocol was registered at clinicaltrials.gov (NCT02778542). The protocol and statistical analysis plan appear as a Supplement.

\section{Study Population}

The study population included primary care patients at four general internal medicine practices at the University of Pennsylvania serving a demographically and socioeconomically diverse population in Philadelphia. Patients were identified from June 2016 to January 2017. We included patients between 18 and 75 years old with a diagnosis of hypertension (ICD-10 I10), a visit to their primary care provider at least twice in the prior 12 months, and at least two out-of-range blood pressure measurements according to JNC8 guidelines $(<150 / 90$ or $<140 /$ 90 if aged 21-59 years or with diabetes or non-diabetic chronic kidney disease), including the most recent visit. Initial blood pressure measurements were obtained from the electronic health record during office visits as recorded by routine clinical practice. Patients needed to have a cellular phone with text messaging capabilities and be on one of the JNC8 medications for hypertension (Online Appendix Table 1). Patients were excluded if they had dementia, severe cognitive impairment, end-stage renal disease, cirrhosis, or metastatic cancer.

\section{Recruitment and Randomization}

All eligible participants received recruitment letters, followed by up to three phone calls from study staff to explain the study, and provide informed consent. After consent, they were asked to complete a brief medication adherence survey. Participants were randomized to usual care, electronic pill bottle, or bidirectional text messaging in a 1:2:2 ratio using variably sized permuted blocks. Randomization was conducted via the Way to Health (WTH) platform, an NIH-funded software platform that facilitates and automates many aspects of study design and intervention implementation. ${ }^{32}$ Participants received $\$ 25$ for participation, and an additional $\$ 75$ for completing the followup appointment at the end of the 4-month study period. Investigators and data analysts were blinded to arm assignment; patients were not blinded due to the nature of the interventions.

\section{Interventions}

Patients in both the pill bottle and bidirectional texting arms received daily feedback about their adherence the day before, along with a reminder to take their medication that day, which was automated by the WTH platform. Participants in the pill bottle arm were mailed a wireless electronic pill bottle (AdhereTech) to be used for one hypertension medication. The pill bottles electronically monitor openings and transmit them to WTH. Participants received one of two daily feedback messages, depending on their adherence the day prior: "Congratulations for taking your medication yesterday! Remember to take your medication today" or, "It looks like you did not take your medication yesterday. Remember to take your medication today."

Participants in the bidirectional texting arm received text messages via the WTH platform, prompting the participant to reply via text with his/her adherence for that day. Since adherence for this arm is patient reported, participants received the following initial message the day of enrollment, "Did you take your medication today? Text back Yes if you have." Mirroring the pill bottle arm, the subsequent days the feedback either stated, "Congratulations for taking your medication yesterday! Did you take your medication today? Text back Yes if you have." Or, "Our records indicated that you did not take all of your medications yesterday. Did you take your medication today? Text back Yes if you have."

Patients in the pill bottle and text messaging arms were monitored for 4 months. Patients randomized to the control arm received usual care as provided by the clinical practice. 


\section{Follow-up Assessment}

All participants were invited to an in-person follow-up appointment 4 months after enrollment. Participants received phone calls and text message reminders for the follow-up appointment. Follow-up appointments were also accepted from a month before to a month after the study end date. Study staff performed the follow-up blood pressure measurement at one of the primary care practices using the Omron 10 blood pressure cuff, which is the same machine that is used for routine office visits. Patients were instructed to sit for 5 min prior to taking their blood pressure. The Omron 10 device takes three readings and uses the average of the three. All participants repeated the brief medication adherence survey at the follow-up appointment. Participants in the pill bottle and text messaging arms were also asked "Please rate how likely you would be to recommend the Way2Text Program to others who are prescribe blood pressure medication on a scale from 0-10? $(0=$ Not At All Likely / 10 = Extremely Likely)."

\section{Study Outcomes}

The primary outcome was the change in systolic blood pressure from the baseline systolic blood pressure reading obtained from the EHR to the 4-month follow-up visit. Additional outcomes were the percent that had controlled blood pressure (according to JNC8 guidelines) during the 4-month visit and the change in diastolic blood pressure from baseline to 4month visit. We tracked BP measurements from the electronic health record that was obtained through office visits. We also compared medication adherence between patients with the electronic pill bottles and the patients with bidirectional messaging. Medication adherence was measured as the proportion of days that the patient opened the pill bottle or responded to the text message. Strict adherence for pill bottles started immediately at the enrollment date. A more relaxed adherence measure started after the first bottle opening. Strict adherence for text messaging only included valid "yes" responses. Relaxed adherence for text messaging counted any confirmation of adherence.

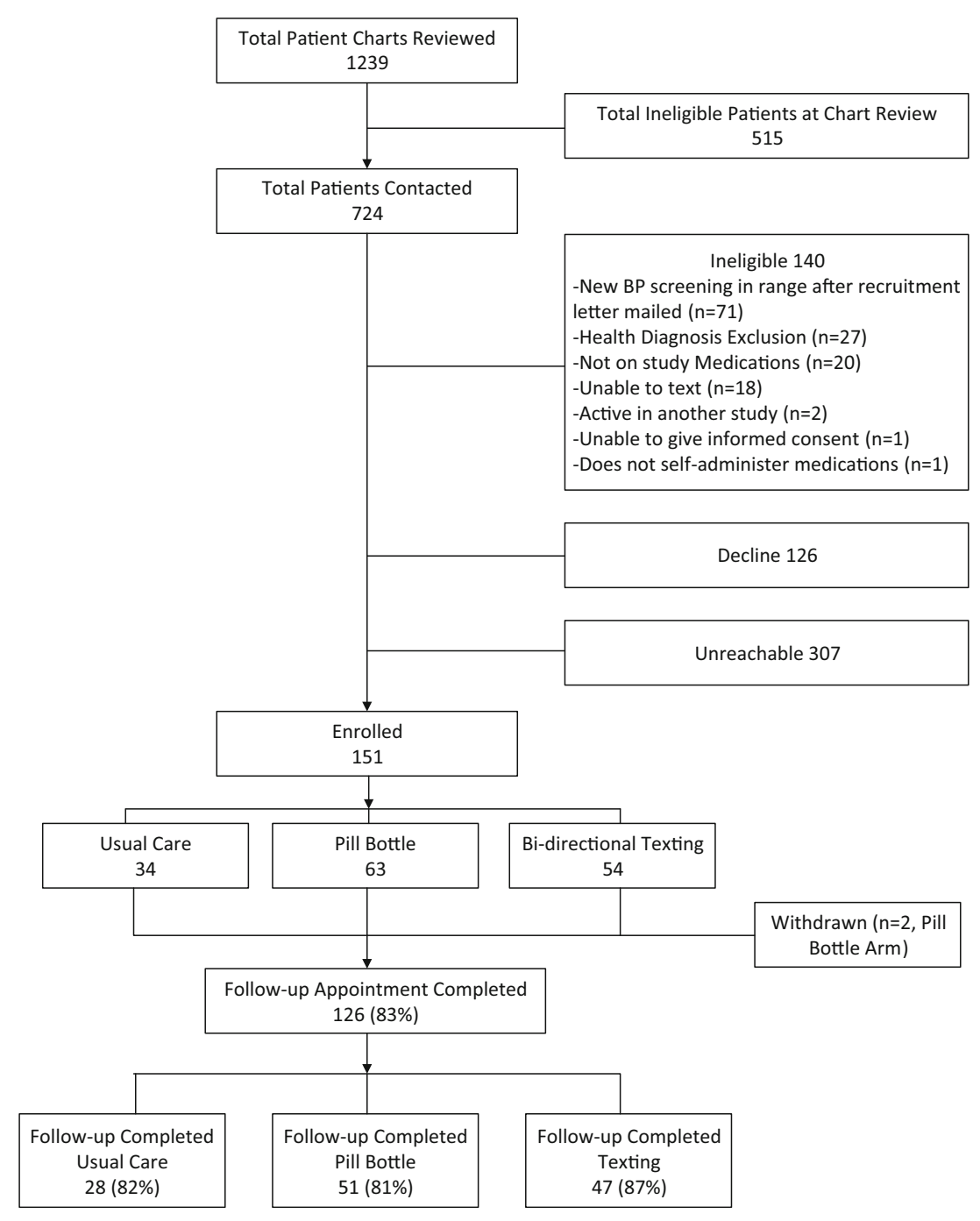

Figure 1 CONSORT diagram. 
Table 1 Demographic Characteristics by Group Assignment

\begin{tabular}{|c|c|c|c|}
\hline & $\begin{array}{l}\text { Control } \\
(n=34)\end{array}$ & $\begin{array}{l}\text { Pill bottle } \\
(n=61)\end{array}$ & $\begin{array}{l}\text { Texting } \\
(n=54)\end{array}$ \\
\hline Female $(\%)$ & $24(71)$ & $35(57)$ & $34(63)$ \\
\hline Age, mean (SD) & $52.7(11.2)$ & $55.2(9.6)$ & $51.0(10.7)$ \\
\hline \multicolumn{4}{|l|}{ Race $(\%)$} \\
\hline Non-Hispanic White & $3(9)$ & $6(10)$ & $7(13)$ \\
\hline Black & $31(91)$ & $55(90)$ & $46(85)$ \\
\hline Other & $0(0)$ & $0(0)$ & $1(2)$ \\
\hline \multicolumn{4}{|l|}{ Insurance type $(\%)$} \\
\hline Commercial & $16(47)$ & $37(61)$ & $29(54)$ \\
\hline Medicare & $8(24)$ & $12(20)$ & $9(17)$ \\
\hline Medicaid & $9(26)$ & $12(20)$ & $12(22)$ \\
\hline Uninsured & $1(3)$ & $0(0)$ & $4(7)$ \\
\hline $\begin{array}{l}\text { Annual income } \$ \text {, } \\
\text { mean (SD) }\end{array}$ & $\begin{array}{l}50,514 \\
(22,063)\end{array}$ & $\begin{array}{l}47,242 \\
(15,248)\end{array}$ & $\begin{array}{l}47,736 \\
(19,073)\end{array}$ \\
\hline Diabetes (\%) & $17(50)$ & $37(61)$ & $26(48)$ \\
\hline $\begin{array}{l}\text { Chronic kidney } \\
\text { disease (\%) }\end{array}$ & $6(18)$ & $5(8)$ & $4(7)$ \\
\hline $\begin{array}{l}\text { 1st baseline SBP, } \\
\text { mean (SD) }\end{array}$ & $154.7(13.5)$ & 153 (14.6) & $152.4(9.7)$ \\
\hline $\begin{array}{l}\text { 1st baseline DBP, } \\
\text { mean (SD) }\end{array}$ & $86.3(9.7)$ & $87.1(11.5)$ & $91.0(8.3)$ \\
\hline $\begin{array}{l}\text { 2nd baseline SBP, } \\
\text { mean (SD) }\end{array}$ & $151.6(11.2)$ & $152.0(11.0)$ & $152.4(12.5)$ \\
\hline $\begin{array}{l}\text { 2nd baseline DBP, } \\
\text { mean (SD) }\end{array}$ & $85.9(10.2)$ & $87.0(11.7)$ & $88.9(12.3)$ \\
\hline
\end{tabular}

Given three pairwise comparisons, significance threshold is $p<.01667$. There are no statistically significant pairwise differences

\section{Statistical Analysis}

Assuming $5.3 \mathrm{mmHg}$ standard deviation of systolic blood pressure (SBP) (given variability of BP over time) and a two-sided significance level of 0.017 (to accommodate three pairwise comparisons), our planned sample size of 60 in each intervention arm and 30 in the control arm provided $80 \%$ power to detect a difference in SBP reduction of $3.75 \mathrm{mmHg}$ between either intervention and usual care, and a difference in SBP reduction of $3.1 \mathrm{mmHg}$ between the electronic pill bottle and bidirectional text messaging arms. Primary analysis included only those patients who attended the follow-up visit. BP measures were compared using Student's $t$ test, and chisquared analysis was used to compare proportion with controlled blood pressure. For missing follow-up BP, we conducted multiple imputation with linear regression using $10 \mathrm{impu-}$ tations and included study arm indicators, demographic variables, and baseline blood pressures as predictors. Analyses were conducted in Stata 14.0 (StataCorp).

\section{RESULTS}

\section{Patient Characteristics}

We conducted chart review on 1239 patients, of whom 724 were sent outreach materials (Fig. 1); 151 enrolled in the trial and were randomized, 34 to usual care, 63 to the electronic pill bottles, and 54 to bidirectional text messaging. Those who declined or were unreachable had similar baseline blood pressure, comorbidities, and gender to the enrolled participants, but were slightly older (mean age 56.0, SD 11.6). Two participants were withdrawn after they were determined to be ineligible after enrollment, and 126 (83\%) completed the followup visit; 149 were included in the intent-to-treat analysis. Participants had a mean age of 53.1 (SD 10.5); 93 (62.8\%) were female; 131 (88.5\%) were black; 79 (53.4\%) had diabetes; and $15(10.1 \%)$ had chronic kidney disease. There were no significant differences across arms (Table 1). The intervention was conducted between June 2016 and June 2017, ending after meeting pre-specified enrollment goals and the followup time frame.

\section{Blood Pressure Outcomes}

At baseline, the mean (SD) systolic blood pressure was $151.6(11.2) \mathrm{mmHg}$ in the usual care arm, 152.0 (11.0) $\mathrm{mmHg}$ in the electronic pill bottle arm, and 152.4 (12.5) $\mathrm{mmHg}$ in the bidirectional text messaging arm. At the 4month follow-up visit, mean (SD) change in systolic blood pressure was -4.7 (23.4) $\mathrm{mmHg}$ in usual care, -4.3 (21.5) $\mathrm{mmHg}$ in the pill bottle arm, and $-4.6(19.8) \mathrm{mmHg}$ in the text arm (Table 2). There was no significant change in systolic blood pressure between control and the pill bottle arm $(p=0.94)$ or the text messaging arm $(p=1.00)$. The two intervention arms did not differ from each other $(p=$ $0.93)$. The proportion that had controlled blood pressure at follow-up was $37.5 \%$ in the usual care arm, $28.1 \%$ in the pill bottle arm, and $25.0 \%$ in the text messaging arm, with no statistically significant difference by arm with $p$ values ranging from 0.23 to 0.72 . There was also no statistically significant change in diastolic blood pressure across arms. After accounting for missing data with multiple imputation and multivariable adjustment, there was also no difference by arms (Online Appendix Tables 2 and 3).

Table 2 Unadjusted Outcomes by Group Assignment

\begin{tabular}{|c|c|c|c|c|c|c|}
\hline & $\begin{array}{l}\text { 1. Control } \\
(n=32)\end{array}$ & $\begin{array}{l}\text { 2. Pill bottle } \\
(n=57)\end{array}$ & $\begin{array}{l}\text { 3. Texting } \\
(n=48)\end{array}$ & $p$ value 1v2 & $p$ value 1v3 & $p$ value $2 \mathrm{v} 3$ \\
\hline \multicolumn{7}{|l|}{ Post } \\
\hline Systolic, mean (SD) & $147.3(22.8)$ & $147.3(21.6)$ & $148.3(16.6)$ & 0.99 & 0.83 & 0.79 \\
\hline Diastolic, mean (SD) & $89.1(14.0)$ & $93.6(14.9)$ & $95.8(12.9)$ & 0.16 & 0.03 & 0.44 \\
\hline \multicolumn{7}{|l|}{ Change } \\
\hline Systolic, mean (SD) & $-4.7(23.4)$ & $-4.3(21.5)$ & $-4.6(19.8)$ & 0.94 & 1.00 & 0.93 \\
\hline Diastolic, mean (SD) & $4.0(12.6)$ & $6.5(15.2)$ & $7.3(14.4)$ & 0.44 & 0.31 & 0.79 \\
\hline \multicolumn{7}{|l|}{ Controlled blood pressure } \\
\hline Controlled blood pressure, no. (\%) & $12(37.5)$ & $57(28.1)$ & $48(25.0)$ & 0.36 & 0.23 & 0.72 \\
\hline
\end{tabular}

Raw p values reported. Given three pairwise comparisons, significance threshold is $p<.01667$ 


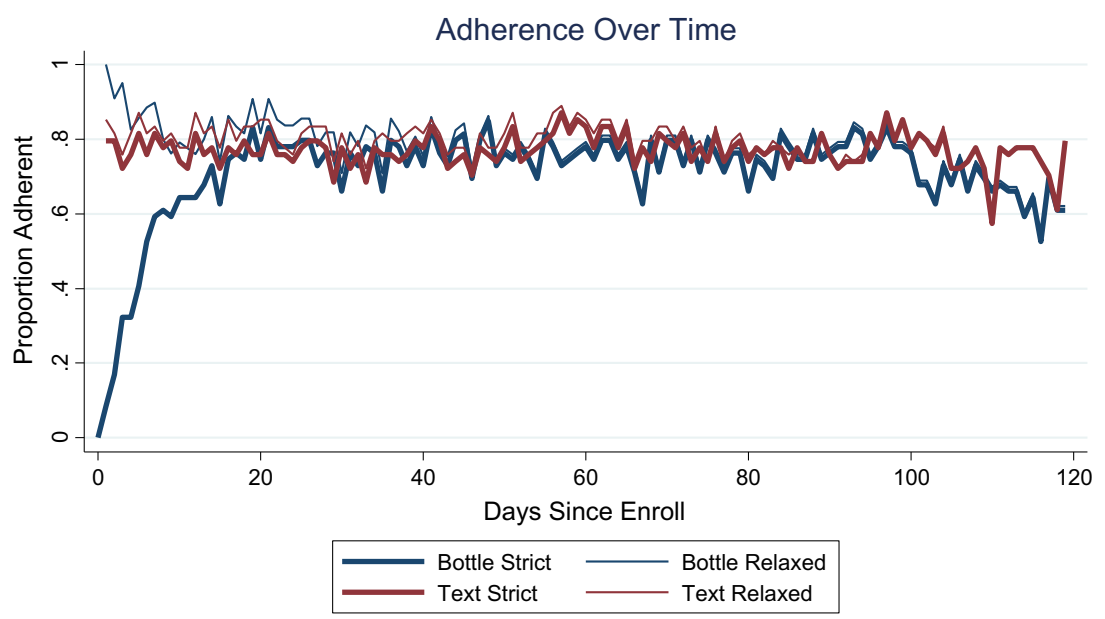

Figure 2 Medication adherence for electronic pill bottle and bidirectional text messaging arms.

\section{Medication Adherence}

Medication adherence rates were $70.8 \%$ and $77.0 \%$ during the intervention for patients in the electronic pill bottles and bidirectional text messaging arms, respectively, using strict criteria (Fig. 2). Using relaxed criteria, pill bottle adherence was $77.2 \%$ and text messaging adherence was $79.4 \%$. There was no significant correlation between adherence with pill bottles or bidirectional text messaging and change in systolic blood pressure (Table 3).

\section{Follow-up Survey}

We found no difference in response to self-reported medication adherence between arms during the baseline and followup assessments. Among the 98 out of 117 participants in the pill bottle and text messaging arms who completed the followup survey, there was a mean likelihood to recommend score of 9.0 out of 10 (SD 2.0), with a median of 10 .

\section{CONCLUSION}

In this trial, patients with uncontrolled hypertension were provided with electronic pill bottles or bidirectional text messaging to monitor medication adherence and provide daily automated feedback for encouragement. Despite high measured medication adherence in both intervention arms, the reduction in systolic blood pressure or blood pressure control was not significantly different than in the control group. We also did not find any correlation of medication adherence measurement with blood pressure control.

Table 3 Correlation Between Medication Adherence and Change in Systolic Blood Pressure

\begin{tabular}{lll}
\hline \hline $\begin{array}{l}\text { Change systolic blood pressure } \\
\text { (SBP) }\end{array}$ & $\begin{array}{l}\text { Pearson's } \\
\text { correlation }\end{array}$ & $\begin{array}{l}\boldsymbol{p} \\
\text { value }\end{array}$ \\
\hline Pill bottle (strict) & -0.14 & .32 \\
Pill bottle (relaxed) & -0.11 & .43 \\
Bidirectional text (strict) & 0.21 & .15 \\
Bidirectional text (relaxed) & 0.13 & .37 \\
\hline
\end{tabular}

There are a few reasons why the interventions in the trial did not show any improvement in blood pressure control in this population. First, adherence to prescribed medications may not be the primary factor leading to poor blood pressure control. Patients need to take the medications, but they also need to have their doses escalated or additional medications prescribed if their blood pressures are persistently elevated. There is evidence from multiple studies demonstrating the frequent inadequacy of medication intensification, which can be attributed to uncertainty about patient adherence, provider inertia, and the visit-based primary care system in which providers have competing demands. ${ }^{33-35}$ Future interventions could encourage dose escalation among providers by incorporating adherence data with targeted messaging to providers in the EHR. ${ }^{36}$ Practices could also assign specialized clinicians to focus on the management of hypertension and reduce the cognitive load on primary care providers.

Second, medication adherence may not have improved enough to have an effect on blood pressure control. While the measured adherence was high in both intervention arms, patients may have needed to have even higher adherence to demonstrate improved blood pressure control as compared with the usual care group. The primary form of motivation was provided through frequent feedback and alerts, which has been shown to increase participation in other studies, although the primary outcomes were measures of medication adherence and not clinical outcomes. ${ }^{17,37}$ However, there is an opportunity to leverage additional insights from behavioral science such as social influence, financial incentives, and manipulations of choice architecture. ${ }^{18,38-41}$ For example, friends or family members could be engaged to encourage adherence or medications could be provided to patients automatically as the default. Medication adherence also may not have been an accurate reflection of true medication adherence as patients may have simply been opening the bottles or responding "yes" to the text messages to avoid negative feedback. There are studies showing that electronic pill bottles are an accurate measure of adherence, ${ }^{12,14,15}$ but there is limited evidence for bidirectional text messaging. 
Third, our patient population may have blood pressure that is particularly difficult to treat. It was mostly African American, who may have blood pressure that is more challenging to treat and control. ${ }^{42-46}$ Additionally, the patient population at this urban academic primary care practice may have had social and economic issues impeding their ability to take their medications. The participating clinics had also initiated different pilot programs such as provider feedback and dedicated hypertension management programs, which may have selected the participants in the study to be particularly difficult to control. Thus, there may be a ceiling effect in this population making remote monitoring less effective, while it may have worked in other patient populations with fewer barriers to control or fewer existing efforts.

Finally, the control group also showed an improvement in blood pressure control, which may have explained the lack of relative benefit in the intervention groups. Those changes might reflect regression to the mean. In addition, control group participants consented to the study, received a financial incentive to participate, and also attended the follow-up blood pressure visit. Each of these elements may have encouraged the patients to take medications and improve their blood pressure. There was also just one follow-up reading of blood pressure, so patients could have simply taken their medications immediately before the last visit and shown improved control.

There are some important limitations to the trial. The patients in this urban academic primary care practice may not be representative of other populations of hypertension patients. We relied on a single blood pressure reading for the primary outcome, ${ }^{47}$ and the initial blood pressure readings were obtained through routine clinical office visits. Our estimate for the standard deviation of systolic blood pressure was lower than what we found during the trial, which limited power to detect the changes in blood pressure. Revised power calculations assuming a standard deviation of $20 \mathrm{mmHg}$ indicate that power would have been approximately $80 \%$ to detect changes in SBP of about $12 \mathrm{mmHg}$ between intervention arms and $16 \mathrm{mmHg}$ between intervention and control arms. Over half of the patients that we attempted to contact were either unreachable or declined to participate, so the enrolled participants may not reflect the characteristics and motivation of the target population. We did not provide feedback to providers about patient medication adherence in this study, and provider feedback might have promoted medication intensification.

This study also has strengths, including the patient-level randomization and the pragmatic nature of the intervention, which was embedded in routine primary care operations. This intervention focused on a particularly vulnerable urban population that included a high proportion of African Americans, a group that is known to have disparities in access and outcomes. ${ }^{48}$ It focused on an important clinical outcome of blood pressure control, measured reliably in a clinic visit. It also addressed an important need, which is to evaluate low-cost and sustainable interventions to improve blood pressure control and increase patient engagement outside of office visits.

Nevertheless, this study suggests that providing electronic pill bottles or bidirectional text messaging with feedback to patients is not sufficient to improve blood pressure control. Future efforts could provide feedback to providers to escalate prescribing of antihypertensive medications, incorporate remote monitoring of blood pressure readings with ongoing feedback to patients, or leverage additional insight from behavioral science to encourage greater engagement and iterative improvement.

Corresponding Author: Shivan J. Mehta, MD, MBA, MSHP; Department of Medicine, Perelman School of Medicine University of Pennsylvania, Philadelphia, PA, USA (e-mail: shivan.mehta@uphs.upenn. edu).

Funding Information This trial was funded by the University of Pennsylvania Health System.

\section{Compliance with Ethical Standards:}

The University of Pennsylvania Institutional Review Board approved the study. Patients provided informed consent prior to enrollment.

Conflict of Interest: Drs. Volpp and Asch are principals at the behavioral economics consulting firm VAL Health. Dr. Troxel serves on the scientific advisory board of VAL Health. Dr. Volpp has received consulting income from CVS Caremark and research funding from Humana, CVS Caremark, Discovery (South Africa), Hawaii Medical Services Association, Oscar, and Weight Watchers. All remaining authors declare that they do not have a conflict of interest.

\section{REFERENCES}

1. Murray CJ, Lopez AD. Measuring the global burden of disease. N Engl J Med. 2013;369(5):448-57.

2. Yoon SS, Fryar CD, Carroll MD. Hypertension Prevalence and Control Among Adults: United States, 2011-2014. NCHS Data Brief. 2015;(220):1-8.

3. Writing Group M, Benjamin EJ, Blaha MJ, Chiuve SE, Cushman M, Das SR, et al. Heart Disease and Stroke Statistics-2017 Update: a report from the American Heart Association. Circulation. 2017;135(10):e146-e603. https://doi.org/10.1161/CIR.0000000000000485.

4. James PA, Oparil S, Carter BL, et al. 2014 evidence-based guideline for the management of high blood pressure in adults: report from the panel members appointed to the eighth joint national committee (jnc 8). JAMA. 2014;311(5):507-20. https://doi.org/10.1001/jama.2013.284427.

5. Egan BM, Zhao Y, Axon RN. US trends in prevalence, awareness, treatment, and control of hypertension, 1988-2008. JAMA. 2010;303(20):2043-50. https://doi.org/10.1001/jama.2010.650.

6. Vrijens B, Vincze G, Kristanto P, Urquhart J, Burnier M. Adherence to prescribed antihypertensive drug treatments: longitudinal study of electronically compiled dosing histories. BMJ. 2008;336(7653):1114-7. https://doi.org/10.1136/bmj.39553.670231.25.

7. Mazzaglia G, Ambrosioni E, Alacqua M, Filippi A, Sessa E, Immordino $\mathbf{V}$, et al. Adherence to antihypertensive medications and cardiovascular morbidity among newly diagnosed hypertensive patients. Circulation. 2009;120(16): 1598-605. https://doi.org/10.1161/circulationaha.108. 830299 . 
8. Matsumura K, Arima H, Tominaga M, Ohtsubo T, Sasaguri T, Fujii K, et al. Impact of antihypertensive medication adherence on blood pressure control in hypertension: the COMFORT study. QJM. 2013;106(10):909-14. https://doi.org/10.1093/qjmed/hct121.

9. Hamdidouche I, Jullien V, Boutouyrie P, Billaud E, Azizi M, Laurent S. Drug adherence in hypertension: from methodological issues to cardiovascular outcomes. J Hypertens. 2017;35(6):1133-44. https:// doi.org/10.1097/hjh.0000000000001299.

10. DiMatteo MR, Giordani PJ, Lepper HS, Croghan TW. Patient adherence and medical treatment outcomes: a meta-analysis. Med Care. 2002;40(9):794-811. https://doi.org/10.1097/01.mlr.0000024612. $61915.2 d$.

11. Asch DA, Muller RW, Volpp KG. Automated hovering in health carewatching over the 5000 hours. N Engl J Med. 2012;367(1):1-3. https:// doi.org/10.1056/NEJMp1203869.

12. Arnsten JH, Demas PA, Farzadegan H, Grant RW, Gourevitch MN, Chang CJ, et al. Antiretroviral therapy adherence and viral suppression in HIV-infected drug users: comparison of self-report and electronic monitoring. Clin Infect Dis. 2001;33(8):1417-23. https://doi.org/10. $1086 / 323201$.

13. van Onzenoort HA, Verberk WJ, Kessels AG, Kroon AA, Neef C, van der Kuy $\mathbf{H}$, et al. Assessing medication adherence simultaneously by electronic monitoring and pill count in patients with mild-to-moderate hypertension. Am J Hypertens. 2009;23(2):149-54.

14. Liu H, Golin CE, Miller LG, Hays RD, Beck CK, Sanandaji S, et al. A comparison study of multiple measures of adherence to HIV protease inhibitors. Ann Intern Med. 2001;134(10):968-77.

15. Lee JY, Kusek JW, Greene PG, et al. Assessing medication adherence by pill count and electronic monitoring in the African American Study of Kidney Disease and Hypertension (AASK) Pilot Study. Am J Hypertens. 1996;9(8):719-25. https://doi.org/10.1016/0895-7061(96)00056-8.

16. Christensen A, Osterberg LG, Hansen EH. Electronic monitoring of patient adherence to oral antihypertensive medical treatment: a systematic review. J Hypertens. 2009;27(8): 1540-51. https://doi.org/10.1097/ HJH.Ob013e32832d50ef.

17. Kessler JB, Troxel AB, Asch DA, Mehta SJ, Marcus N, Lim R, et al. Partners and alerts in medication adherence: a randomized clinical trial J Gen Intern Med. 2018. https://doi.org/10.1007/s11606-018-4389-7.

18. Mehta SJ, Troxel AB, Marcus N, Jameson C, Taylor D, Asch DA, et al. Participation rates with opt-out enrollment in a remote monitoring intervention for patients with myocardial infarction. JAMA Cardiol. 2016;1(7):847-8. https://doi.org/10.1001/jamacardio.2016.2374.

19. Santschi V, Rodondi N, Bugnon O, Burnier M. Impact of electronic monitoring of drug adherence on blood pressure control in primary care: a cluster 12-month randomised controlled study. Eur J Intern Med 2008;19(6):427-34. https://doi.org/10.1016/j.ejim.2007.12.007.

20. Sabin LL, DeSilva MB, Hamer DH, Xu K, Zhang J, Li T, et al. Using electronic drug monitor feedback to improve adherence to antiretroviral therapy among HIV-positive patients in China. AIDS Behav. 2010;14(3):580-9. https://doi.org/10.1007/s10461-009-9615-1.

21. de Bruin M, Hospers HJ, van Breukelen GJ, Kok G, Koevoets WM, Prins JM. Electronic monitoring-based counseling to enhance adherence among HIV-infected patients: a randomized controlled trial. Health Psychol. 2010;29(4):421-8. https://doi.org/10.1037/a0020335.

22. Cole-Lewis H, Kershaw T. Text messaging as a tool for behavior change in disease prevention and management. Epidemiol Rev. 2010;32:56-69. https://doi.org/10.1093/epirev/mxq004.

23. Finitsis DJ, Pellowski JA, Johnson BT. Text message intervention designs to promote Adherence to Antiretroviral Therapy (ART): a metaanalysis of randomized controlled trials. PLOS ONE. 2014;9(2):e88166. https://doi.org/10.1371/journal.pone.0088166.

24. Thakkar J, Kurup R, Laba TL, Santo K, Thiagalingam A, Rodgers A, et al. Mobile telephone text messaging for medication adherence in chronic disease: a meta-analysis. JAMA Intern Med. 2016;176(3):340-9. https://doi.org/10.1001/jamainternmed.2015.7667.

25. Paola V, Mónica A, Carlos A, Claudia S, Carlos N, Ana G, et al. Mobile phone text messaging improves antihypertensive drug adherence in the community. J Clin Hypertens.. 2017;19(12):1276-84. https://doi.org/ $10.1111 /$ jch. 13098

26. Bobrow K, Farmer AJ, Springer D, Shanyinde M, Yu L-M, Brennan T, et al. mobile phone text messages to support treatment adherence in adults with high blood pressure (StAR): a single-blind, randomized trial Circulation. 2016. https://doi.org/10.1161/circulationaha.115.017530.

27. Márquez Contreras E, de la Figuera von Wichmann M, Gil Guillén V, Ylla-Catalá A, Figueras M, Balaña M, et al. Effectiveness of an intervention to provide information to patients with hypertension as short text messages and reminders sent to their mobile phone (HTAAlert). Aten Primaria. 2004;34(8):399-405. https://doi.org/10.1016/ s0212-6567(04)78922-2.

28. Buis L, Hirzel L, Dawood RM, Dawood KL, Nichols LP, Artinian NT, et al. Text messaging to improve hypertension medication adherence in african americans from primary care and emergency department settings: results from two randomized feasibility studies. JMIR mHealth uHealth. 2017;5(2):e9. https://doi.org/10.2196/mhealth.6630.

29. Margolis KL, Asche SE, Bergdall AR, Dehmer SP, Groen SE, Kadrmas HM, et al. Effect of home blood pressure telemonitoring and pharmacist management on blood pressure control: a cluster randomized clinical trial. JAMA. 2013;310(1):46-56. https://doi.org/10.1001/jama.2013. 6549.

30. Bosworth HB, Powers BJ, Olsen MK, McCant F, Grubber J, Smith V, et al. Home blood pressure management and improved blood pressure control: results from a randomized controlled trial. Arch Intern Med. 2011;171(13):1173-80. https://doi.org/10.1001/archinternmed.2011.276.

31. Omboni S, Guarda A. Impact of home blood pressure telemonitoring and blood pressure control: a meta-analysis of randomized controlled studies. Am J Hypertens. 2011;24(9):989-98. https://doi.org/10.1038/ajh.2011.100.

32. Asch DA, Volpp KG. On the way to health. LDI Issue Brief. 2012;17(9): 1-4.

33. Oliveria SA, Lapuerta P, McCarthy BD, L'Italien GJ, Berlowitz DR, Asch SM. Physician-related barriers to the effective management of uncontrolled hypertension. Arch Intern Med. 2002;162(4):413-20.

34. Hyman DJ, Pavlik VN. Self-reported hypertension treatment practices among primary care physicians: blood pressure thresholds, drug choices, and the role of guidelines and evidence-based medicine. Arch Intern Med. 2000;160(15):2281-6.

35. Gbenga O. Barriers to optimal hypertension control. J Clin Hypertens. 2008;10(8):644-6. https://doi.org/10.1111/j.1751-7176.2008.08329.x.

36. Kronish IM, Moise N, McGinn T, Guan Y, Chaplin W, Gallagher BD, et al. An electronic adherence measurement intervention to reduce clinical inertia in the treatment of uncontrolled hypertension: the MATCH cluster randomized clinical trial. J Gen Intern Med. 2016;31(11):1294300. https://doi.org/10.1007/s11606-016-3757-4.

37. van Heuckelum M, van den Ende CHM, Houterman AEJ, Heemskerk CPM, van Dulmen S, van den Bemt BJF. The effect of electronic monitoring feedback on medication adherence and clinical outcomes: a systematic review. PLOS ONE. 2017;12(10):e0185453. https://doi.org/ 10.1371/journal.pone.0185453.

38. Asch DA, Troxel AB, Stewart WF, Sequist TD, Jones JB, Hirsch AG, et al. Effect of financial incentives to physicians, patients, or both on lipid levels. JAMA. 2015;314(18):1926-35. https://doi.org/10.1001/jama. 2015.14850

39. Volpp KG, Loewenstein G, Troxel AB, Doshi J, Price M, Laskin M, et al. A test of financial incentives to improve warfarin adherence. BMC Health Serv Res. 2008;8(1):272. https://doi.org/10.1186/1472-6963-8-272.

40. Long JA, Jahnle EC, Richardson DM, Loewenstein G, Volpp KG. Peer mentoring and financial incentives to improve glucose control in african american veterans: a randomized trial. Ann Intern Med 2012;156(6):416-24. https://doi.org/10.7326/0003-4819-156-6201203200-00004.

41. Thaler RH, Sunstein CR, Balz JP. "Choice Architecture." Chapter 25 in Eldar Shafer, ed., The Behavioral Foundations of Public Policy, Princeton University Press. 2013.

42. The ALLHAT Officers and Coordinators for the ALLHAT Collaborative Research Group. Major outcomes in high-risk hypertensive patients randomized to angiotensin-converting enzyme inhibitor or calcium channel blocker vs diuretic: The antihypertensive and lipid-lowering treatment to prevent heart attack trial (ALLHAT). JAMA. 2002;288(23):2981-97. https://doi.org/10.1001/jama.288.23.2981.

43. Leenen FH, Nwachuku CE, Black HR, Cushman WC, Davis BR, Simpson LM, et al. Clinical events in high-risk hypertensive patients randomly assigned to calcium channel blocker versus angiotensinconverting enzyme inhibitor in the antihypertensive and lipid-lowering treatment to prevent heart attack trial. Hypertension (Dallas, Tex. : 1979). 2006;48(3):374-84. https://doi.org/10.1161/01.HYP.0000231662. 77359.de.

44. Nwankwo T, Yoon SS, Burt V, Gu Q. Hypertension among adults in the United States: National Health and Nutrition Examination Survey, 20112012. NCHS Data Brief. 2013(133):1-8.

45. Fryar CD, Ostchega Y, Hales CM, Zhang G, Kruszon-Moran D. Hypertension prevalence and control among adults: United States, 2015-2016. NCHS Data Brief. 2017(289):1-8.

46. Ferdinand KC, Yadav K, Nasser SA, Clayton-Jeter HD, Lewin J, Cryer DR, et al. Disparities in hypertension and cardiovascular disease in 
blacks: the critical role of medication adherence. J Clin Hypertens (Greenwich, Conn.). 2017;19(10):1015-24. https://doi.org/10.1111/jch. 13089.

47. Banegas JR, Ruilope LM, de la Sierra A, Vinyoles E, Gorostidi M, de la Cruz JJ, et al. Relationship between clinic and ambulatory bloodpressure measurements and mortality. N Engl J Med. 2018;378(16):1509-20. https://doi.org/10.1056/NEJMoa1712231.
48. Lackland DT. Racial differences in hypertension: implications for high blood pressure management. Am J Med Sci. 2014;348(2):135-8. https:// doi.org/10.1097/MAJ.0000000000000308.

Publisher's Note Springer Nature remains neutral with regard tojurisdictional claims in published maps and institutional affiliations. 